\title{
Using Autonomous Underwater Vehicles as Sensor Platforms for Ice-Monitoring
}

\author{
Petter Norgren Roger Skjetne
}

Department of Marine Technology, Norwegian University of Science and Technology (NTNU), NO-7491 Trondheim, Norway. E-mails: \{petter.norgren, roger.skjetne\}@ntnu.no.

\begin{abstract}
Due to the receding sea-ice extent in the Arctic, and the potentially large undiscovered petroleum resources present north of the Arctic circle, offshore activities in ice-infested waters are increasing. Due to the presence of drifting sea-ice and icebergs, ice management (IM) becomes an important part of the offshore operation, and an important part of an IM system is the ability to reliably monitor the ice conditions. An autonomous underwater vehicle (AUV) has a unique capability of high underwater spatial and temporal coverage, making it suitable for monitoring applications. Since the first Arctic AUV deployment in 1972, AUV technology has matured and has been used in complex under-ice operations. This paper motivates the use of AUVs as an ice-monitoring sensor platform. It discusses relevant sensor capabilities and challenges related to communication and navigation. This paper also presents experiences from a field campaign that took place in Ny-Ålesund at Svalbard in January 2014, where a REMUS 100 AUV was used for sea-floor mapping and collection of oceanographic parameters. Based on this, we discuss the experiences related to using AUVs for ice-monitoring. We conclude that AUVs are highly applicable for ice-monitoring, but further research is needed.
\end{abstract}

Keywords: AUV; Arctic technology; Ice management; Ice intelligence; Ice monitoring.

\section{Introduction}

According to the National Snow and Ice Data Center (2014) the Arctic had a record low sea-ice extent during the summer of 2012, where the ice extent dropped below 4 million square kilometers. In 2013 and 2014, the sea-ice extent had a minimum extent slightly above 5 million square kilometers, but as the sixth and seventh lowest extent measured since the satellite records began in 1979, it reinforces the long-term downward trend in Arctic sea-ice extent. In addition, it has also been reported that the mean Arctic sea-ice thickness has been reduced from 3.64 meters in 1980 to 1.89 meters in 2008 (Farmer and Cook, 2013), and that the multi-year ${ }^{1}$ ice is decreasing at a higher rate than the younger, thinner ice.

\footnotetext{
${ }^{1}$ Sea-ice that has survived one summer or more.
}

An assessment made by the United States Geological Survey (Gautier et al., 2009) concludes that approximately $30 \%$ of the world's undiscovered gas and $13 \%$ of the world's undiscovered oil can be found in the Arctic, and with the decreasing sea-ice extent during summer, these resources are becoming more attractive. As offshore activities move into Arctic waters, where sea-ice and icebergs may threaten installations and structures, ice management (IM) becomes an important part of the offshore operation. An important part of an IM system, is the detection, tracking, and drift forecasting of ice features (Eik, 2008).

Eik and Løset (2009) discussed requirements for one or more unmanned underwater vehicle (UUV), preferably untethered due to sea-ice interaction with the tether, for tracking of icebergs detected by stationary sensor platforms, and for continuous monitoring of an 


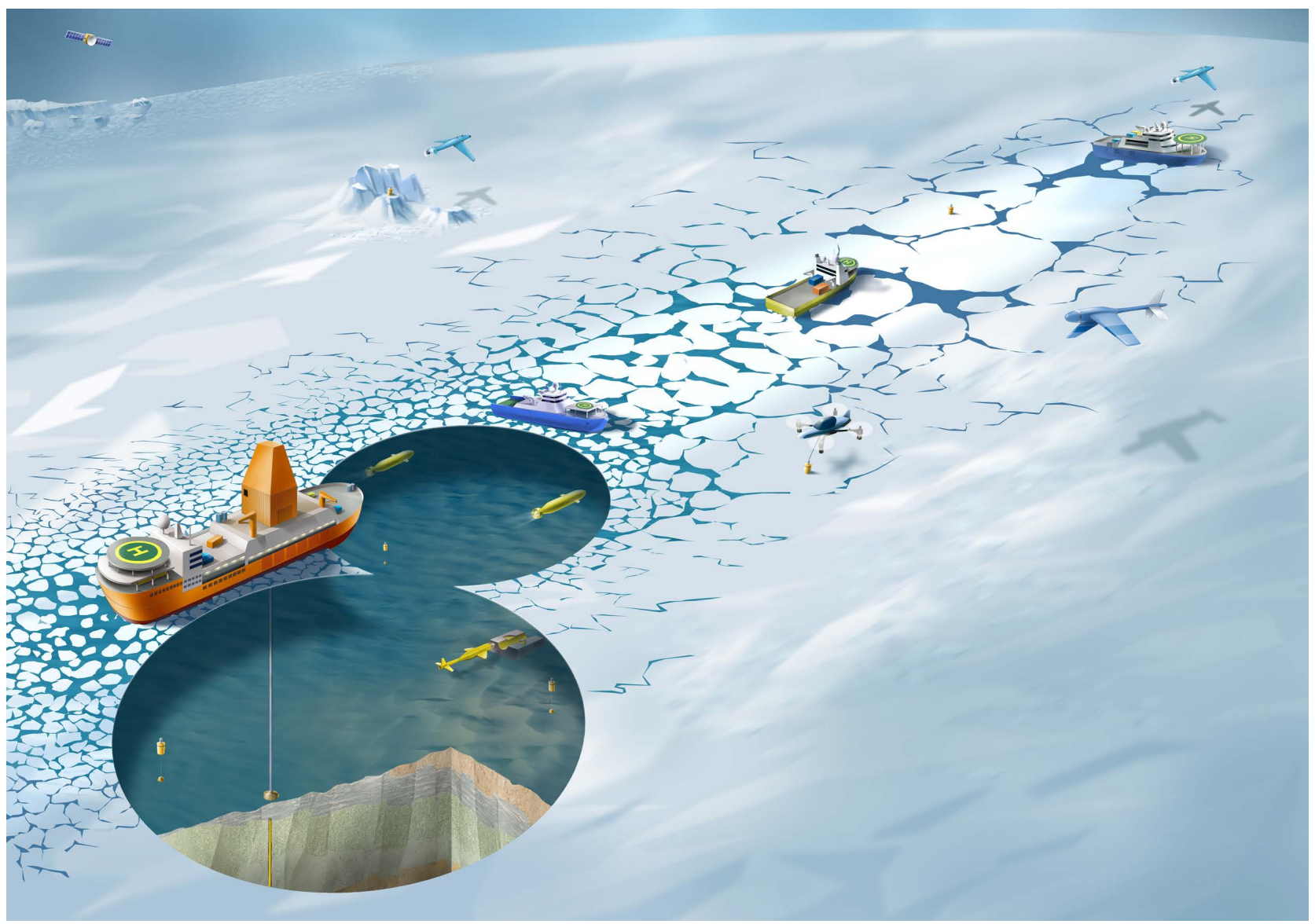

Figure 1: Illustration of a possible future Arctic drilling operation: an Arctic drillship on DP, aided by icebreakers and unmanned vehicles. Illustration: Bjarne Stenberg. Copyright: NTNU.

area upstream of a protected installation. Autonomous underwater vehicles (AUVs) is a class of untethered UUVs that have been demonstrated in the Arctic in several operations (see e.g. Thorleifson et al. (1997), Wadhams et al. (2006), Bellingham et al. (2008), or Kaminski et al. (2010)), and have the advantage of being unaffected by the potentially harsh surface conditions in the Arctic. Dependent on configuration, AUVs can reach water depths of several thousand meters, and the endurance varies from hours to a few days. AUVs are often highly modular, and thus, the sensor suite can be configured to suit the desired application.

The main objectives of this paper are to motivate use of AUVs as ice-monitoring sensor platforms for IM operations, and to report experiences related to this application from an AUV deployment in the Arctic polar night. Firstly, Section 2 will introduce ice management systems and the different modules that make up a IM system, including a summary of previous Arctic AUV deployments. Section 3 discusses capabilities of AUVs and presents different aspects that must be considered before employing AUVs for ice-monitoring, and Sec- tion 4 presents the experiences from AUV deployments during a campaign that took place in $\mathrm{Ny}$-Ålesund at Svalbard in January 2014.

\section{Ice management and previous work on AUVs in the Arctic}

Figure 1 illustrates a possible future Arctic drilling operation. An Arctic drillship is keeping position by means of dynamic positioning (DP), which means that the vessel is keeping its position by means of thruster power, possibly aided by moorings. This means that the amount of ice loads the vessel can withstand while still keeping position is limited, and thus, the presence of sea-ice and icebergs means that ice management is required. As illustrated in Figure 1, the vessel is assisted by icebreakers to reduce the incoming ice loads by breaking the ice into more manageable ice floes, and one or several unmanned vehicles are used to monitor the incoming ice. This constitutes a part of an IM system. 


\subsection{Ice management}

Eik (2008) gives the following definition of ice management:

Definition 1. Ice management is the sum of all activities where the objective is to reduce or avoid actions from any kind of ice features. This will include, but is not limited to:

- Detection, tracking, and forecasting of sea-ice, ice ridges and icebergs.

- Threat evaluation.

- Physical ice management such as ice breaking and iceberg towing.

- Procedures for disconnection of offshore structures applied in search for, or production, of hydrocarbons.

Detection and tracking of ice features has previously been performed by visual observations from ice observers, marine radars, ice drift buoys, airborne reconnaissance, and satellites (Eik, 2008), but most of these surveillance methods suffer from reduced quality in fog and bad weather - a common occurrence in the Arctic. Satellites operating at wavelengths $>0.9 \mathrm{~cm}$ (microwave) can penetrate clouds and polar darkness, but suffers from a tradeoff between spatial coverage and resolution (Lubin and Massom, 2006), and online update rate. Due to the high latitudes in the Arctic, satellites do not give sufficient temporal resolution.

Eik and Løset (2009) presents specifications for a subsurface ice intelligence system, and concludes that technology for mapping the underside of the ice, and for detecting and identifying icebergs and multi-year ice will contribute to increased operational safety. Haugen et al. (2011) describes the structure of an ice observer system, intended to provide an aid for decision making and risk assessment on IM operations, and also motivates the use of unmanned aerial vehicles (UAV) for ice-monitoring.

\subsection{AUVs in Arctic operations}

From the first reported AUV deployment in the Arctic in 1972, presented by Francois and Nodland (1972), more and more complex AUV missions have been conducted in the Arctic. A good example in this context is the cable-laying AUV, Theseus, which successfully laid a $175 \mathrm{~km}$ long fiber-optical cable between Jolliffe Bay and Ice Camp Knossos in Canada, under a 2.7 meter thick ice cover (Thorleifson et al., 1997; Ferguson, 1998).

AUVs have the unique capability of being able to survey the underside of the ice over large areas. Wadhams et al. (2004) presents the use of a Maridan Martin 150 AUV that gathered side-scan imagery of the underside of the ice in 2002 - the first of its kind acquired by an AUV. From the side-scan sonar data, the authors were able to identify first-year, multi-year, brash, and frazil ice. Similarly, the Autosub-II AUV was used to obtain the first under-ice multibeam measurements in 2004 (Wadhams et al., 2006).

To assess how the climate changes in the Arctic are affected by the inflow of warm Atlantic water through the Fram strait and into the Arctic Ocean, and its effect on the global climate, large scale oceanographic surveys are necessary. The Atlantic Layer Tracking Experiment (ALTEX), was designed to answer this question by surveying the water column with a custom designed AUV, capable of ranges between 1500 and 3000 $\mathrm{km}$ and with a depth rating of up to $4500 \mathrm{~m}$. Missions conducted in the Arctic, on latitudes as high as $82^{\circ}$ north are presented by Bellingham et al. (2008).

More recently, in 2010, the Explorer AUV, developed by International Submarine Engineering Ltd., was launched from Boden Island and collected underice bathymetry for 12 days without surfacing, see Kaminski et al. (2010) and Ferguson (2011). The AUV transited from the main camp to a remote camp on a drifting ice floe $320 \mathrm{~km}$ away, where underwater charging and data download was demonstrated. From the remote camp, several bathymetric surveys were conducted, and a total of $1000 \mathrm{~km}$ of bathymetric data was acquired under ice during the operation.

For a more detailed survey on UUVs in Arctic operations the reader is referred to Norgren et al. (2014), and references therein.

\section{Capabilities of AUVs for ice-monitoring applications}

Synthetic aperture radar (SAR) satellites can estimate sea-ice thickness from measurements of the ice freeboard $^{2}$, and by using estimates of the sea-ice density (Laxon et al., 2013). Uncertainties like snow loading, and uncertain ice density, will contaminate the ice thickness estimates. Also, the estimate will only provide an average sea-ice thickness, thus, erasing features like ridge keels ${ }^{3}$. Similarly, Marine Radars have problems with detecting ice features accurately in large sea states (O'Connell, 2008). Large sea states are not a problem when operating around a continuous ice cover, but the retreat of sea ice also affect the wave heights. Thomson and Rogers (2014) reports that the increased open water area in the Beaufort sea during the summer

\footnotetext{
${ }^{2}$ Surface elevation of the sea-ice above the water surface.

${ }^{3}$ Part of ridge extending into the water.
} 


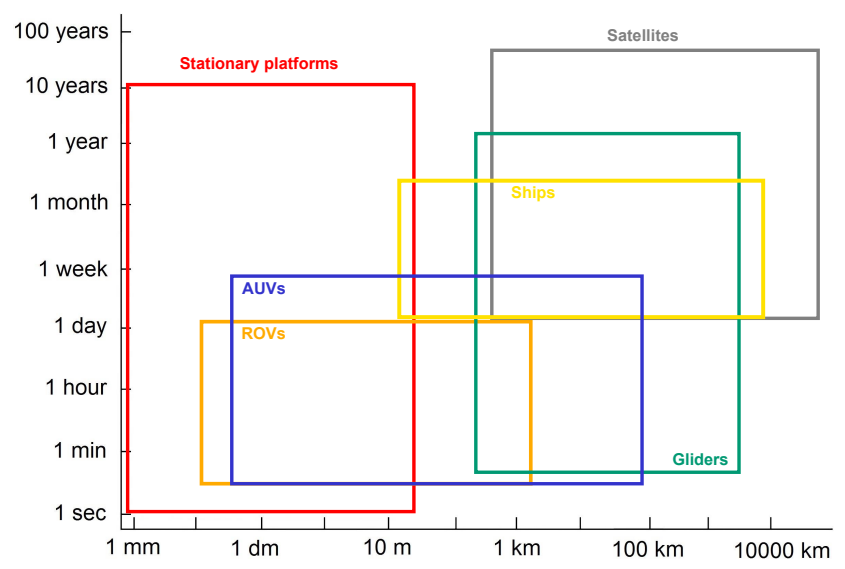

Figure 2: Spatial and temporal scales and resolutions of different sensor platforms. Figure is based on Strommel diagram in (Nilssen et al., 2015). Left/lower part of a box means resolution, while the right/upper part of a box means scale. Note that the scale of the axes are nonlinear, and the numbers are only for providing an indication.

of 2012 allowed waves to evolve into swells, and that these results suggest that larger waves in the Arctic are to be expected in the future.

Sea-ice features are much more dominant on the underside of the ice, than above. For example, the ridge keel depth to sail ${ }^{4}$ height ratio is reported to have a mean value of 4.4 (Timco and Burden, 1997). This motivates the use of an underwater sensor platform for monitoring of sea-ice, and AUVs have a relatively large spatial and temporal scale, while still maintaining a high spatial and temporal resolution (see Figure 2). This section will go through the capabilities of AUVs with respect to ice-monitoring, and present challenges and technological barriers that must be managed before AUVs can be used for this purpose.

\subsection{Sensor capabilities for ice-monitoring}

Due to high attenuation of shortwave electromagnetic (EM) radiation in water, acoustics are widely used in different sensor technology in underwater vehicles, both for data collection (e.g. sonars), and for navigation and communication. An acoustic wave is a pressure wave that propagate through a medium, and is characterized by its intensity, its frequency, and the length of the pulse (Blondel, 2010, Chapter 1). In the following, several acoustic sensors relevant for ice-monitoring will be presented. Figure 3 illustrates an AUV with multibeam echosounder (MBE), sides-

\footnotetext{
${ }^{4}$ Part of ridge extending above the sea-ice surface.
}

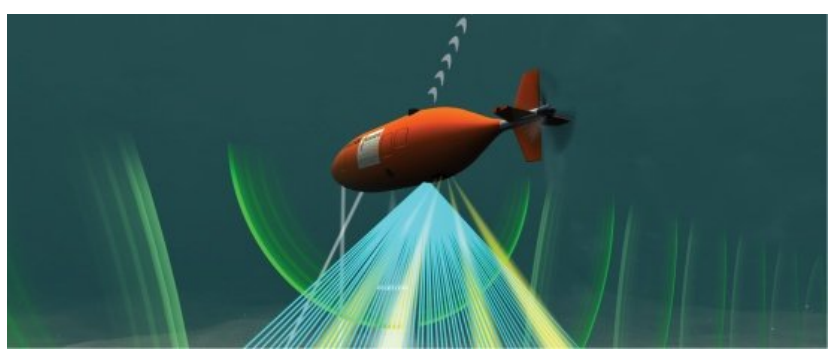

Figure 3: An AUV using MBE, SSS, and ADCP. MBE: blue beams, SSS: Green waves, and ADCP: yellow beams. Image courtesy of Fugro Survey Ltd. (http://www.fugrosurvey.co.uk).

can sonar (SSS), and acoustic Doppler current profiler $(\mathrm{ADCP})$.

\subsubsection{Sidescan sonar}

The SSS is mounted on the sides of the AUV, and transmits one fan-shaped acoustic beam to each side of the vehicle (see Figure 3). To cover as large range as possible, the beams are wide across-track the vehicle path, and narrow along-track. Most of the acoustic wave transmitted from the sonar (at an elevation angle) will be reflected off the sea bottom, at the same angle as the incoming wave (the reflection angle), and only a fraction of the wave will propagate back to the sonar (Blondel, 2010, Chapter 1). The amplitude of the backscattered sound received by the SSS are used to create an acoustic image of the environment, where objects that reflect differently than the sea bottom can be identified. SSS, on the contrary to multibeam sonars, have only one receiver per transducer.

The first SSS images of the underside of the ice was captured from the British nuclear submarine HMS Sovereign beneath the Arctic ocean in October 1976 (Wadhams, 1978). Sear and Wadhams (1992) present an analysis of sidescan sonar imagery from $140 \mathrm{~km}$ of under ice transit, collected with another British submarine in 1987. From the SSS imagery, ridges and multi-year ice was classified, but the authors state that first-year ice was hard to classify, and several ridges was not identified.

The first SSS imagery from the underside of the ice collected with an AUV was presented by Wadhams et al. (2004). From this data, the authors are able to calculate the ice draft directly above the two transducers, and to identify smooth surfaced first-year ice, as well as multi-year ice with depressions and bulges. In addition, brash and frazil ice, and open water was classified from the imagery.

Forrest et al. (2012) presents the use of the University of British Columbia (UBC) Gavia AUV to map 
fragments of the Petermann Ice Island (PII) in the Canadian High Arctic. An interferometric sidescan sonar was used for collecting a terrain map of the underside of the PII-B fragment using the AUV, and the side of the PII-B, PII-Ba and Berghaus fragments were mapped using a ship-mounted multibeam echosounder. By combining the multibeam measurements and the sidescan measurements, a digital 3D model of a part of the PII-B fragment was made. Forrest et al. (2012) state that one of the biggest challenges during the operation was AUV navigation under a drifting and rotating reference frame, and the ability to plan the missions accordingly.

\subsubsection{Multibeam echosounder}

MBEs have generally been used for creating bathymetry maps of the sea floor. Echo sounders operate by transmitting an acoustic pulse and listening for the received echo. By measuring the time from the ping was transmitted to the echo was received, the range to the sea floor (or other targets) can be estimated. A multibeam sonar consist of groups of projector arrays and hydrophone arrays (L-3 Communications, 2000). A projector array is isotropic sources $^{5}$ placed in such a manner that the beams that are formed are narrow and directed, rather than an isotropic expansion of the pressure wave (L-3 Communications, 2000). Hydrophone arrays are used to receive sound waves, and one hydrophone array is only sensitive to sound waves originating from a specific direction (L-3 Communications, 2000). This process, producing narrow transmit and receive beams, is called beam forming (L-3 Communications, 2000). Since the narrow beams only ensonifies a small area, many beams can be used to create a high resolution 3D map of the target being mapped (see Figure 3 for an illustration).

In August 2004, the Autosub-II AUV was operated off NE Greenland, and the first multibeam data of the underside of the ice was obtained (Wadhams et al., 2006). During the mission, $450 \mathrm{~km}$ of high resolution sonar data was acquired, and ridges, with maximum draft of more than 30 meters, was identified, as well as first- and multi-year ice. Kaminski et al. (2010), on the other hand, presents a mission where $1000 \mathrm{~km}$ of MBE bathymetry data was collected from an AUV, operating under ice for 12 days without being removed from the water.

Sonar-based iceberg-relative AUV navigation by using MBE measurements are discussed by Kimball and Rock (2008), where the authors present a method to

\footnotetext{
${ }^{5}$ Isotropic sources create pressure waves with isotropic expansion, which is the circular pattern created by e.g. throwing a stone into water.
}

develop a digital terrain map of an iceberg to be used in terrain-aided navigation for drift-free relative positioning.

\subsubsection{Acoustic Doppler current profiler}

An ADCP is an acoustic instrument that transmits sound at a fixed frequency, and uses the Doppler shift in the received backscatter to estimate relative velocity between the instrument and the scatterers (Teledyne RD Instruments, 2011). By assuming that the scatterers in the water column (typically Euphasiid, Pteropod, and Copepod) float in the ocean with the same average speed as the current, ADCPs can be used for estimating the ocean current (Teledyne RD Instruments, 2011). Bottom-tracking is an application of Doppler velocity $\log (\mathrm{DVL})^{6}$ that are used for navigation, since it measures the relative velocity between the instrument and the sea floor. Only radial motion causes Doppler shift, that is changes in distance between instrument and scatterers (Teledyne RD Instruments, 2011). This means that only translational velocity can be measured from ADCPs, not angular velocities.

For ice-monitoring applications, an ADCP can be used for measurements of ice - instrument relative velocity (McEwen et al., 2005). With knowledge of the vehicle velocity, the absolute velocity of the ice can be estimated, but due to limited range of ADCPs and the deep waters in many places in the Arctic, it can not be assumed that AUVs will have bottom-tracking capability when performing ice-monitoring. Ice-relative navigation with AUVs are discussed by e.g. McEwen et al. (2005) and Forrest et al. (2008).

\subsection{Communication}

As stated by Eik and Løset (2009), an important part of an ice intelligence system is the ability to transfer a sufficient amount of data from the sensors, to a central ice management team, typically onboard the drilling vessel, or an icebreaker. Communications from an AUV is usually performed by means of acoustics, and the Arctic causes an especially challenging acoustic environment due to multipath formation by the sound waves' repeated interactions with the ice cover (O'Hara and Collis, 2011). In addition to these challenges, the available bandwidth in underwater acoustic communication is limited by transmission losses, and these losses increase with both increased frequency and increased range (Stojanovic, 1996).

At lower frequencies, the ice cover in the Arctic will have less effect on the acoustic waves, but at very low

${ }^{6} \mathrm{An}$ ADCP can be employed as a DVL. 
frequencies, the sound is not trapped effectively in the ocean and interactions with the sea bottom can cause high losses (O'Hara and Collis, 2011). Freitag et al. (2012) reports tests of under ice communications, and of the four tested frequencies $(12,24,48$ and $96 \mathrm{~Hz})$, the $12 \mathrm{~Hz}$ bandwidth was the most reliable, with the highest signal-to-noise ratio (SNR) over the whole range (20 - $75 \mathrm{~km})$. Johnson et al. (1994) presents testing of an acoustic communications network of six nodes, and communication with the Odyssey AUV moving through the network. The network was deployed over an area of 15 square $\mathrm{km}$ in an ice covered lake, and over an area of 22 square $\mathrm{km}$ in the Beaufort Sea, and communicated with a host PC over radio Ethernet. During the tests, a frequency of $15 \mathrm{kHz}$ was used, and a data rate of 5 kilobytes per second (kbps) was typical. The network proved reliable in the lake, but in the Arctic too much ambient noise caused connectivity issues. The $15 \mathrm{kHz}$ frequency used by Johnson et al. (1994) is much higher than the $12 \mathrm{~Hz}$ frequency that was found by Freitag et al. (2012) to be the most reliable over their test range, but the range in the tests reported by Johnson et al. (1994) is much lower than in the tests reported by Freitag et al. (2012).

\subsubsection{Communication requirements for online monitoring applications}

A possible acoustic communication system for continuous ice-monitoring with AUVs include the deployment of an acoustic network at the area where the ice is being monitored. As IM operations will seldom be conducted without surface vessel assistance (e.g. icebreakers), these can be used as communication relays transmitting data over radio frequency to a centralized IM decision center.

The limited bandwidth of the acoustic communication network require the AUVs to autonomously decide what data to transmit. For example, the Imagenex DeltaT MBE, operating at a frequency of $260 \mathrm{kHz}$ with 480 beams, will acquire 5 megabytes (MB) of data per minute (or approximately $85 \mathrm{kbps}$ ) (Imagenex, 2011). In addition to the MBE data, other data acquired by the AUV will also be relevant for IM decisions support (e.g. ADCP data for ice drift and current estimates, and navigation data from the AUV). This results in a considerable amount of data if a typical data transfer rate of $5 \mathrm{kbps}$ is assumed (as reported by Johnson et al. (1994)).

Due to the large amount of data relevant for IM decision support, alternative ways of representing data, to reduce the amount of data to be transferred, are attractive. An example highly relevant to ice-monitoring in this context, is the ice topography estimator presented by Jørgensen and Skjetne (2015). The topog- raphy estimator presented in the referred article uses measurements of the ice topography, e.g. from a MBE, and represents the topography of the ice using a truncated Fourier series, with relatively few coefficients, that easily can be managed by an acoustic communication channel.

\subsection{Navigation}

\subsubsection{Acoustic navigation}

Since EM waves do not propagate far under water, it is impossible to use global navigation satellite systems (GNSS) for underwater vehicles, except when at the surface. As with communication, acoustics are often used for navigation of AUVs. Two acoustic systems that are widely used for navigation of underwater vehicles are long baseline (LBL) and ultra-short baseline (USBL) (Kinsey et al., 2006).

With LBL, a transducer placed on the vehicle communicates with at least 3 transponders to obtain an unique north-east position through trilateration ${ }^{7}$, or with at least 4 transponders (at least one in a different plane than the others) for an unique north-east-down position trough quadlateration ${ }^{7}$. Note that quadlateration is seldom used for underwater vehicles, since the pressure sensor usually provide a more reliable depth measurement. For example, a $12 \mathrm{kHz}$ LBL system can operate at a maximum range of $5-10 \mathrm{~km}$, with a range precision of $0.1-10 \mathrm{~m}$, and an update rate of $0.1-1 \mathrm{~Hz}$ (Kinsey et al., 2006). Higher frequency of the acoustic signal will give higher precision and higher update rate, but the range is reduced.

USBL, on the other hand, measures range and bearing between a transducer and a transponder (e.g. placed on a ships hull, or on a sub-sea station). In under-ice applications, USBL can be used to give the underwater vehicle a homing capability, so it can return to e.g. a hole in the ice. Bellingham et al. (1994) reports an example of this application, where the vehicle typically returned to within $30 \mathrm{~cm}$ of the homing transponder. Note that both LBL and USBL navigation systems only provide a relative navigation reference. For absolute positioning, the total navigation error is limited to the precision of the placement of the transponders, often recorded with GPS, which can have a precision of $10 \mathrm{~m}$. For more details on underwater acoustic positioning systems, the reader is referred to Milne (1983).

\footnotetext{
${ }^{7}$ Lateration - Position determination through distance measurements.
} 


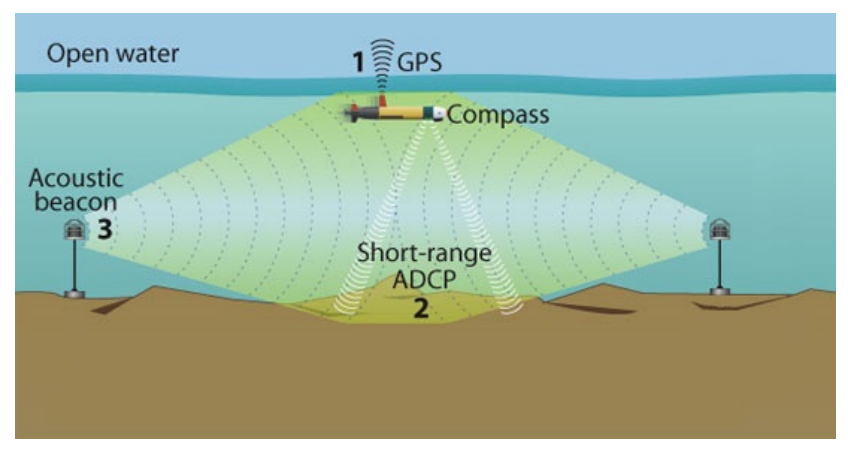

Figure 4: Illustration of an AUV utilizing GPS (1), ADCP (2), acoustic transponders (3), and possibly inertial navigation. Image courtesy of Jayne Doucette, WHOI (http://whoi.edu).

\subsubsection{Inertial navigation}

Inertial navigation systems rely on measurements from inertial measurement units (IMU), that is, gyroscopes and accelerometers, to provide a continuous estimate of position, attitude, and linear and angular velocities. A good reference on INS is provided by Britting (1971). The heading of the vehicle is determined either by a magnetic compass, by integrating measurements of yaw rate from a gyroscope, or from a north-seeking gyrocompass. At Arctic latitudes, the magnetic compass will become unreliable due to the near vertical magnetic field (McEwen et al., 2005). North-seeking gyrocompasses utilize the rotation of the earth and the earth's gravitational field (Kinsey et al., 2006), and at Arctic latitudes the horizontal component of the earth's rotation will become too small, and gyrocompasses become unreliable. Therefore, neither magnetic compasses, nor gyrocompasses are suitable for Arctic navigation alone (McEwen et al., 2005). An INS using gyroscopes for determining heading, need an external heading reference (magnetic compass, or GPS, if the vehicle is moving in the surface) for alignment purposes. McEwen et al. (2005) chose an integrated gyrobased INS/DVL/GPS solution as the primary navigation sensor, since this provides an accurate heading estimate once calibrated (but drifts over time if not corrected).

An INS is often coupled with position estimates from GNSS, acoustic positioning systems, and with velocity measurements from an ADCP. Figure 4 illustrates an AUV that utilizes GPS when it is in the surface, ADCP when in range of the sea-bottom, an acoustic positioning system when with range, and possibly inertial navigation when no other position references are available. INS aided by velocity measurements can obtain very low navigation errors over relatively long du- rations (Kinsey et al., 2006). For underwater vehicles, position updates from GNSS only occurs at the surface, and the rate of acoustic position systems can be quite low, making inertial navigation an important part of an underwater vehicle's navigation suite.

According to Jalving et al. (2004), the main contributors to position drift in a DVL aided INS is error in the body-fixed velocity, and error in heading. The velocity error are mainly determined by the accuracy of the DVL itself $(0.2 \%$ of distance traveled (DT) for a $1200 \mathrm{kHz}$ DVL according to Jalving et al. (2004)). Heading error will be a function of gyro drift (in the range $0.005-1^{\circ} / \mathrm{h}$ for AUV navigation systems), and for a gyrocompass the heading error will also be a function of latitude. For example, for a gyrocompass with a drift of about $0.005^{\circ} / \mathrm{h}$, the across-track error will be about $0.05 \%$ at $45^{\circ}$ latitude, and $0.2 \%$ DT at $80^{\circ}$ latitude (see Jalving et al. (2004)). Therefore, in long missions, or missions without accurate velocity measurements, some sort of position measurements should be made, to correct the unbounded error that is an inherent problem of pure inertial navigation.

\subsection{Technology demands for continuous ice-monitoring applications}

For extended underwater operations, like a continuous monitoring application, several factors may limit the duration of the operation. Most AUVs depend on battery power, and have limited endurance before charging is required. As discussed in Section 3.3, underwater navigation is a challenge, and some sort of means for eliminating the unbounded error of inertial navigation must be present for extended AUV operations. Furthermore, it may be undesirable to have a human operator controlling high-level decisions, like where to monitor, or when to return for charging - introducing a higher demand for autonomy. The technological challenges related to continuous underwater monitoring application will be discussed subsequently.

\subsubsection{Docking stations}

An ice-mounted system for underwater charging and data downloading is presented by King et al. (2009). This docking system was designed for the Explorer AUV, to limit the logistical demands (e.g. drilling of larger hole in the ice, and cranes for lifting) of deployment and recovery of the AUV from the ice. The docking station had the ability to rotate the AUV while held, for INS calibration purposes and for aligning the AUV with the current while docked. Capture of the vehicle was performed by the means of a small size remotely operated vehicle (ROV), which attached a tether to the AUV. A refined version of the docking 
system was demonstrated successfully in the Arctic by Kaminski et al. (2010).

As offshore exploration will be performed in a given area for an extended period of time, deploying subsea infrastructure may be justified economically. Hobson et al. (2007) provides a short summary of previous work on docking stations for AUVs, and discusses the development and testing of a sub-sea docking station, which may be more relevant for ice-monitoring. The docking station provides inductive power transfer, and wireless data transfer - limiting the need for maintenance demanding moving parts. A USBL homing system provides a navigation reference for the navigation system, and capture and release can be performed autonomously.

\subsubsection{Navigation networks}

In addition to docking stations, a network of sub-sea acoustic navigation sensors, placed at known positions, is essential for navigating over a long period of time in deep water. With a network of sensors, redundancy can be used to provide enhanced accuracy, to detect and reject erroneous measurements, or to increase reliability of the network in case of malfunctions. For the $2 \mathrm{D}$ case, where depth is measured from a pressure sensor, at least four transponders are necessary for redundancy checks (Milne, 1983). An example of an acoustic communication network can be seen in Figure 5 .

As an alternative to sub-sea infrastructure for acoustic navigation, Santos et al. (2008) presents a solution for relative navigation using moving transponders, placed on surface vessels. In this scheme, the AUV does not know its global position, but moves in a pattern relative to the moving transponders. By re-organizing the transponder locations, external control of the AUV trajectory can be achieved. Another solution that limits the need for sub-sea infrastructure, is a communication and navigation network where AUVs are utilized as mobile sensor nodes, see e.g. Rice (2005).

\subsubsection{Autonomy}

In the majority of the reported AUV missions up to today, the AUV operate with a pre-programmed mission plan, defining the entire mission. Hagen et al. (2007) defined two conceptual classes of decision autonomy: the ability to handle malfunctions, and the ability to react to external events. The former class of autonomy is a key component for operations in extreme environments, like the Arctic (see e.g. Ferguson (1998) and Kunz et al. (2009)), while the latter is important for optimizing resource usage. Examples of applications of AUVs basing decisions on sensor readings are given by Cruz and Matos (2010) and Wiig et al. (2012).

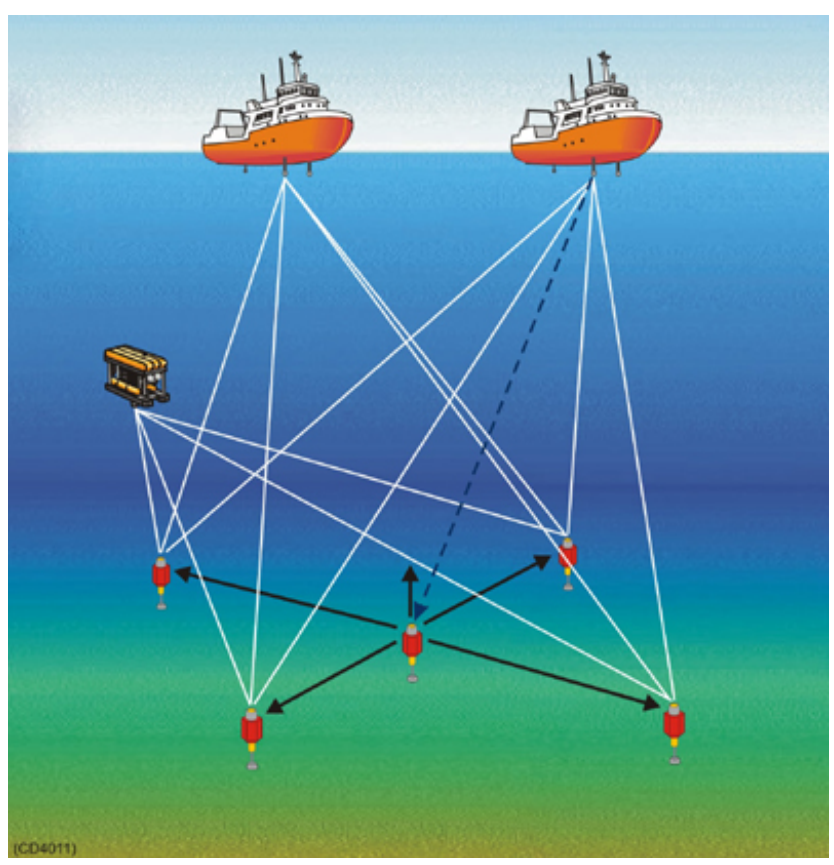

Figure 5: Long baseline acoustic navigation network. Image courtesy of Kongsberg Maritime (http://km.kongsberg.com).

For ice-monitoring applications, autonomy will be a vital component, due to communication constraints and reliability requirements. The AUV must detect, classify, and track identified ice features, based on measurements, and autonomously decide what information to relay to the IM decision center. The AUV must also handle malfunctions in an appropriate, fail-safe manner, without intervention from an operator.

\section{REMUS in the Arctic polar night}

In the 9 day period between January $16^{\text {th }}$ and January $24^{\text {th }}$ in 2014 , a field campaign was conducted at the research settlement in $\mathrm{Ny}$-Ålesund at Svalbard in Norway. The field campaign was a part of a course at the University Centre at Svalbard (UNIS), called "Underwater robotics in the Arctic polar night". A Remote Environmental Monitoring UnitS (REMUS) AUV was used throughout the campaign, for seafloor mapping, and for mapping of spatial and temporal distribution of oceanographic variables. Through this section, the details of the NTNU REMUS AUV will be outlined, and experiences related to using AUVs as ice-monitoring sensor platforms will be discussed. 


\subsection{The NTNU REMUS 100 AUV}

An illustration of the NTNU REMUS 100 AUV can be seen in Figure 6. This AUV is a propeller driven, torpedo-shaped AUV capable of diving to 100 meters depth, and has a rated endurance of about 10 hours at a speed of $2 \mathrm{~m} / \mathrm{s}$. A detailed description of a similar REMUS 100 unit is described by Moline et al. (2005). Its small size and low weight makes it deployable by two people from a small boat, simplifying the operation significantly. The AUV specifications are seen in Table 1.

The navigation sensor suite consist of a GPS antenna, an LBL high frequency acoustic navigation transducer, a $1200 \mathrm{kHz}$ RD Instruments Workhorse Navigator ADCP and a Honeywell HG1700AG58 IMU. A minimum of two LBL transponders must be deployed before the acoustic positioning system will provide a relative position (two transponders give two unique positions, but the AUV assumes which is correct based on the estimated position). Typical range of the LBL network is about $2 \mathrm{~km}$ and the LBL navigation error comes primarily from misplacement of the transponders, while the precision of the acoustic range measurements are about $2 \%$. The downward-looking ADCP will provide a speed measurement when the vehicle is within 30-40 meters from the bottom (bottomtracking).

If the vehicle is outside the ADCP range, the speed will be estimated from the acoustic position fixes, or if unavailable, propeller revolutions. If the transducers are not deployed, or if the vehicle is out of range of the acoustic network, the Navigation Processing Suite (NavP) will perform inertial navigation, aided by the ADCP, IMU, and the pressure sensor. The HG1700AG58 is a high performance IMU with three ring laser gyroscopes $(1 \% \mathrm{~h}$ bias) and three quartz resonating beam accelerometers. The gyroscopes in the IMU are not north-seeking and, thus, require assistance from the magnetic compass, or GPS, during initialization. If the vehicle is in range for bottom-tracking, the

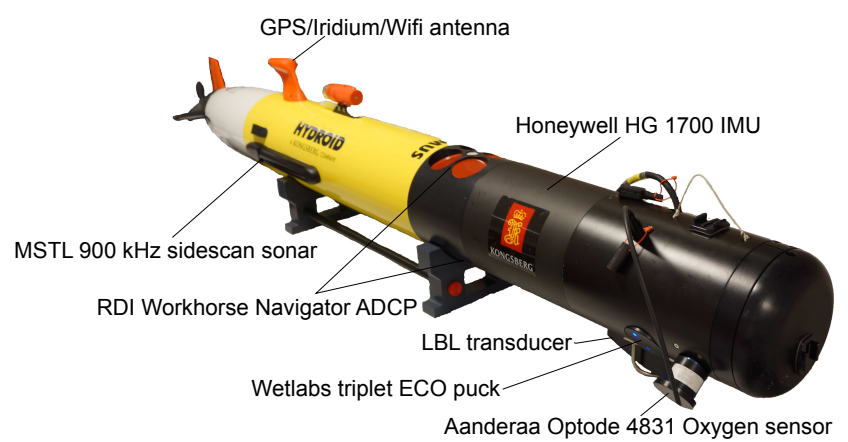

Figure 6: The NTNU REMUS 100 AUV.
Table 1: The NTNU REMUS specifications.

\begin{tabular}{|l|c|}
\hline Parameter & Value \\
\hline Vehicle diameter & $0.19 \mathrm{~m}$ \\
\hline Vehicle length & $1.6 \mathrm{~m}$ \\
\hline Weight in air & $31 \mathrm{~kg}$ \\
\hline Max operational depth & $100 \mathrm{~m}$ \\
\hline Speed range & 0.25 to $2.57 \mathrm{~m} / \mathrm{s}$ \\
\hline Battery & $4 \times 250$ Wh Lithium-ion \\
\hline Typical endurance & 10 hours @ $2 \mathrm{~m} / \mathrm{s}$ \\
& 14 hours @ $1.5 \mathrm{~m} / \mathrm{s}$ \\
\hline
\end{tabular}

navigation accuracy is about $2 \%$ DT.

If the vehicle is outside range for bottom-tracking, the inertial navigation capability will be severely limited. ADCP water-tracking ${ }^{8}$ could reduce this limitation, but this feature was not implemented on the AUV at the time of the campaign. If the error in the INS grows too large, the vehicle will revert to dead-reckoning mode, and base its position on a magnetic compass, and the propeller revolutions per minute (RPM), when no acoustic position measurements are available. The navigation accuracy in deadreckon mode is about $4 \% \mathrm{DT}$, but will be dependent on oceanographic and geographic conditions.

The oceanographic sensor package on the NTNU REMUS 100 consists of a Wetlabs Environmental Characterization Optics (ECO) Puck, an Aanderaa Optode 4831 Oxygen sensor, a Neil Brown Ocean Sensors Inc. conductivity, temperature, and depth (CTD) sensor, and a Marine Sonics Technology Ltd $900 \mathrm{kHz}$ Sidescan sonar. The ECO Puck provide measurements of Chlorophyll a (Chl a) concentration, colored dissolved organic matter (cDOM), and optical backscatter at a wavelength of $470 \mathrm{~nm}$ at 117 degrees $\left(\beta\left(117^{\circ}\right.\right.$, $470 \mathrm{~nm}))$. The optical backscatter is related to total suspended matter (TSM) in the water column. The oxygen optode provides measurements of the oxygen concentration, and oxygen saturation in the water, while the CTD sensor provides measurements of salinity, temperature, and depth. From these measurements the sound speed profile can be estimated, and corrected sound speed is made available to other sensors that rely on this data for correcting measurements (e.g. the acoustic positioning system).

The sidescan sonar on the NTNU REMUS vehicle has a maximum operating range of 50 meters, and an acoustic cross-track resolution of $1 \mathrm{~cm}$. Ideally, the altitude of the vehicle should be $1 / 10$ th of the sidescan range.

${ }^{8}$ Water-tracking - inertial navigation aided by water-mass velocity information. 


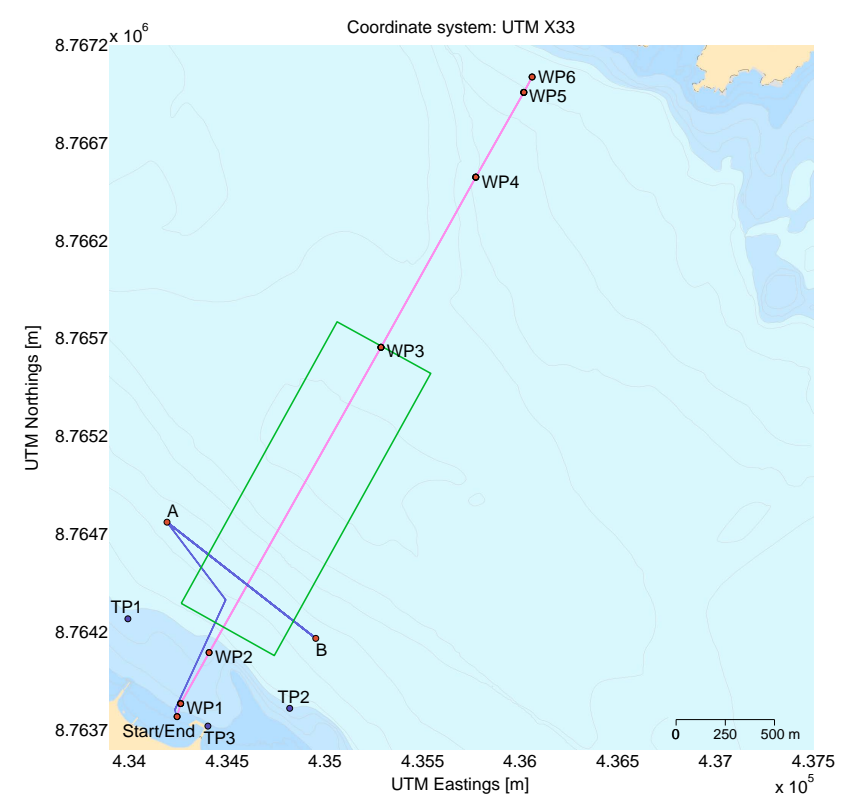

Figure 7: Planned AUV surveys for the campaign. Blue line - Zooplankton survey that was repeated four times at different times of the day (transect A-B). Pink line - Cross-fjord survey (WP 1-6).

\subsection{Navigation in the Arctic polar night}

Figure 7 illustrates the planned paths for the AUV missions conducted in Ny-Ålesund. The blue line in Figure 7 shows a mission that was repeated four times with the objective of mapping spatial and temporal variability of zooplankton in the water column, and the pink line shows a mission crossing the Kings Bay outside $\mathrm{Ny}$-Ålesund to gather measurements of oceanographic parameters across the fjord. Due to the deep water, the missions would be run without bottom-tracking. Running without bottom-tracking for extended periods of time caused the error in the INS errors to grow too large, and the AUV reverted to using the onboard magnetic compass and propeller RPM for dead-reckoning, in addition the acoustic positioning system when available. A position drift due to uncertainties in the magnetic compass was expected when the AUV was outside the range of the LBL network (the estimated LBL coverage area is illustrated in Figure 7). Therefore, surface and GPS-fix objectives were added at intervals to correct accumulated errors. The depth controller reference for the cross-fjord mission was an undulating pattern with a depth rate setpoint of $15 \mathrm{~m} / \mathrm{min}$, varying between a minimum depth of $5 \mathrm{~m}$ and a maximum depth of $80 \mathrm{~m}$. The depth controller for the zooplankton survey was a periodic pattern, where the transect A - B (see Figure 7) was transited using undu-

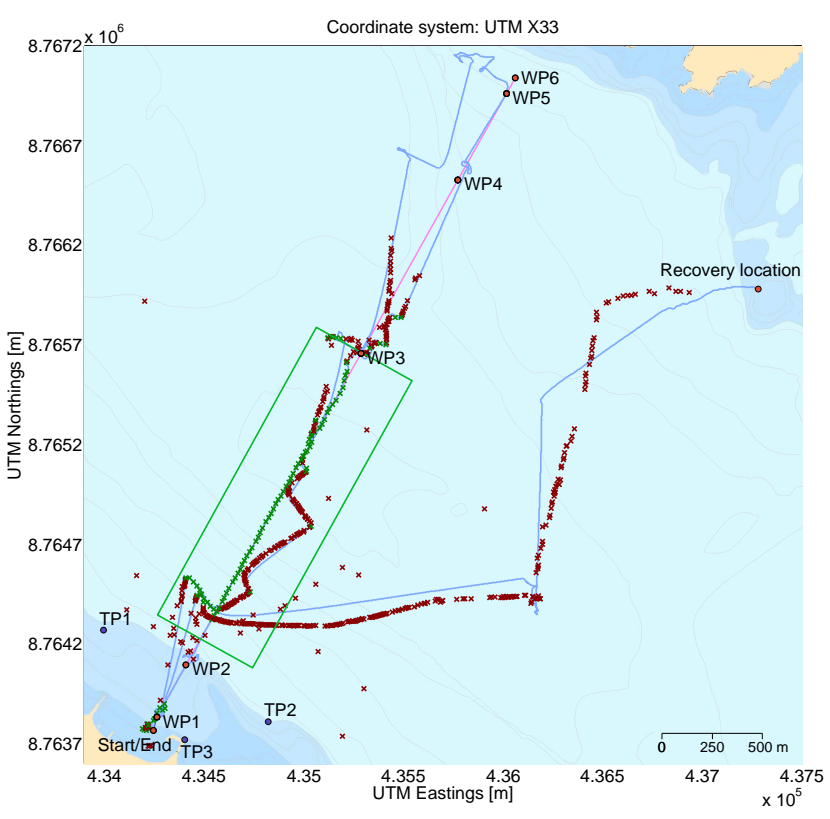

Figure 8: AUV trajectory for the cross-fjord survey. Blue line: Re-navigated trajectory calculated by the REMUS VIP software. Green/red crosses: Good/bad LBL fixes respectively.

lating depth controller (with slightly different settings between missions, but similar to the controller used for the cross-fjord survey), and then the A - B transect was run three times at constant depth, where the depth setpoints was $15 \mathrm{~m}, 35 \mathrm{~m}$, and $75 \mathrm{~m}$, respectively. Then the pattern was repeated (the number of times the pattern was repeated was different between missions). A summary of the conducted surveys can be found in Table 2. In the mission conducted on the $23^{\text {rd }}$ of January, the transect was transited solely with the undulating pattern, and the mission performed on $24^{\text {th }}$ of January was the cross-fjord survey.

Figure 8 shows a plot of the calculated AUV trajectory for the cross-fjord survey mission, as well as good and bad LBL position fixes. The actual trajectory was estimated with Hydroid's REMUS Vehicle Interface Program (VIP) software.

The first run across the fjord was performed successfully, but due to a limited amount of good LBL fixes the AUV drifted a significant distance from the intended survey line, even inside the area with LBL coverage. Outside the LBL network coverage area, the cross-track error at surfacing on the first dead-reckoning transect (between WP3 and WP4) was about $250 \mathrm{~m}$, which was more than anticipated (more than $20 \%$ DT). The return transect was transited with significantly less crosstrack error, and good LBL fixes was obtained within the coverage area. A GPS fix was acquired after the AUV surfaced at WP2, and the AUV transited to WP1 
Table 2: REMUS mission statistics. Mission duration, distance traveled, and percentage good LBL fixes reported by the REMUS VIP, made by Hydroid. Standard deviations calculated by the NavLab software (Gade, 2004). NavP data was not available for the cross-fjord survey mission.

\begin{tabular}{|l|c|c|c|c|c|c|}
\hline $\begin{array}{l}\text { Mission start } \\
\text { [date/time UTC] }\end{array}$ & $\begin{array}{l}\text { Mission } \\
\text { duration } \\
\text { [h:mm:ss] }\end{array}$ & \multirow{2}{*}{$\begin{array}{l}\text { Distance } \\
\text { traveled [m] }\end{array}$} & & \multirow{2}{*}{$\begin{array}{l}\text { Good LBL } \\
\text { fixes [\%] }\end{array}$} & \multicolumn{3}{|l|}{ Measured position STD } \\
\cline { 5 - 7 } & & & 48.18 & 1.2819 & 1.4290 & 0.0240 \\
\hline 2014-01-18 12:29:35 & $2: 28: 41$ & 13869 & 37.73 & 1.3078 & 1.7082 & 0.0183 \\
\hline $2014-01-21 \quad 10: 02: 31$ & $2: 53: 24$ & 13964 & 47.88 & 1.0636 & 1.5480 & 0.0224 \\
\hline $2014-01-21 \quad 20: 59: 10$ & $3: 18: 45$ & 17828 & 45.72 & 1.9790 & 2.2245 & 0.0230 \\
\hline $2014-01-23 \quad 09: 53: 45$ & $4: 55: 56$ & 27426 & & N/A & N/A & N/A \\
\hline 2014-01-24 09:37:39 & $2: 49: 38$ & 15504 & 7.96 & & & \\
\hline
\end{tabular}

before heading north again. The AUV drifted to the west, but attempted to correct its course after a few good LBL fixes. An investigation of the AUVs fault log reveals warnings of too large compass bias estimates, and incorrect heading measurements caused the AUV to continue on a wrong course, heading east. After a surface objective and a position error of approximately 1400 meters, the AUV corrected its course again. The compass bias terms were altered, but were still not correct. As can be seen in Figure 8, the AUV was recovered after automatically aborting its mission on the other side of the fjord, since it was unable to reach its intended destination.

The problems related to navigation in the cross-fjord survey is believed to stem mainly from a bad magnetic compass calibration at the start of the mission. Investigation of the fault log exported from the vehicle, reveals 32 warnings related to large compass bias, where the bias changed between 18.6 degrees and -55.3 degrees. In addition to the compass problems, bad LBL coverage was experienced during most of the mission, and as can be seen from Table 2 (the cross-fjord survey was the mission conducted on the $24^{\text {th }}$ of January), only $7.96 \%$ of the LBL fixes was accepted by the navigation system. The reason for the bad LBL coverage remains unknown, but it could originate from acoustic wave interaction with ice. As the AUV was recovered, several large pieces of floating ice was observed in the fjord. While it is not considered likely that an ice piece with a large enough draft to shadow the transponders was present, the ice pieces could cause a challenging acoustic environment due to reflections from the ice.

\subsection{Experiences related to AUV ice-monitoring applications}

While the main objective of the surveys conducted at Svalbard was related to biological studies, several aspects that are relevant to an ice-monitoring application was present. This includes the presence of drifting ice, severely limited visibility throughout the cam- paign, navigation at Arctic latitudes, and communication constraints.

The presence of drifting ice does not pose a treat for the AUV while performing its mission underwater. However, several surface objectives with subsequent GPS fixes were performed in the fjord. The AUV has no knowledge over what is above it, and a collision with one of the ice pieces could have had dramatic consequences (e.g. breaking of the GPS antenna, or hull damage). For ice-monitoring applications, the AUV should not rely on GPS fixes for performing its mission, but sooner or later a surface will be necessary. A solution where the AUV returns to a moonpool in a vessel by a homing system could be chosen, or the AUV could search for an area of open water (within a certain area) autonomously. In areas with ice features with large drafts (ridges or icebergs), collision avoidance should be employed.

The presence of sea-ice also requires a high precision acoustic positioning system for navigation at Arctic latitudes, since ice-monitoring is likely to be an operation lasting for days or even weeks. A robust INS is needed for periods without acoustic position updates, and a fallback system is necessary if the acoustic positioning system is out of range/operation for an extended period of time. One solution could be to use terrain aided navigation, where MBE measurements are used with a bathymetric map of the area (Carreño et al., 2010). The drawback of this solution in an icemonitoring application, is that the AUV need to be within MBE range of the sea floor, while to obtain measurements of the sea-ice, the AUV need to be relatively near the surface.

Limited visibility is not a problem for the AUV under operation, but it does complicate human factors involved in deployment and recovery operations. Deployment and recovery with limited visibility must be taken into account, since the polar night lasts for months in large parts of the Arctic. An advantage with the darkness is that if lights are mounted on the AUV, the AUV is very easy to spot. 
Even if the air temperature in the Arctic may drop below $-50{ }^{\circ} \mathrm{C}$, the temperature of the water will be close to zero, and improper storage and handling of equipment can have detrimental consequences. For example, Ferguson (2008) states that a consequence of too large temperature gradients can be cracked seals and consequent leakages in the vehicle.

Communication is an integral part of an icemonitoring application. For an offshore operation extending over a long period, it may be economically viable to place a permanent acoustic and communication grid, perhaps even with underwater docking stations - limiting the need for deployment and recovery of AUVs drastically. A supervisory system could be used to schedule resources, monitor battery levels, and deploy AUVs where it is necessary. If an AUV loses acoustic communication with the grid for a certain amount of time, the AUV could decide to return to the docking station to upload ice data. The supervisory system, having lost communication with one (or more) AUVs, would schedule new resources to the specified areas while the returning AUVs upload data.

\section{Conclusion}

As ice features are more dominant on the underside of the ice, IM systems will need subsurface iceinformation to gain an accurate picture of the ice loads in an area. AUVs have the ability to monitor the subsurface ice features, and can cover relatively large spatial and temporal scales, regardless of weather conditions - making AUVs a suitable platform for icemonitoring. The case study from Svalbard shows that underwater navigation is an area that still requires research, but autonomous failure detection and handling is also important to increase the reliability of AUVs. In addition, communication rate constraints and endurance limitations, makes continuous monitoring a challenge. Due to these challenges, sub-sea infrastructure (docking stations, acoustic communication and navigation networks) are recommended if employing AUVs for ice-monitoring. Increased autonomy will also be a criterion for ice-monitoring using AUVs the AUV must be able to detect, track, and report relevant ice features automatically and reliably. In addition, autonomous supervisory systems, and decision support systems will be necessary when applying AUVs for ice-monitoring.

\section{Acknowledgments}

This work was supported by the Research Council of Norway (RCN) through the Centre for Research-based
Innovation SAMCoT (RCN-project 203471), the Centre of Excellence AMOS (RCN-project 223254), and KMB Arctic DP (RCN-project 199567). The authors also thank the NTNU Applied Underwater Robotics laboratory (AUR-lab) for facilitating experimental resources, and the research project Marine Night (RCNproject 226417), and the University Centre in Svalbard for for facilitating the field work through the UNIS course AB334/834 "Underwater robotics and polar night biology". The authors acknowledge Professor Martin Ludvigsen and Dr. Morten Breivik, for their constructive comments and excellent feedback - thank you for providing inputs for improving the quality of this work.

\section{References}

Bellingham, J. G., Cokelet, E. D., and Kirkwood, W. J. Observation of warm water transport and mixing in the Arctic basin with the ALTEX AUV. In IEEE/OES Autonomous Underwater Vehicles. Woods Hole, MA, USA, pages 1-5, 2008. doi:10. 1109/AUV. 2008.5290527.

Bellingham, J. G., Goudey, C. A., Consi, T. R., Bales, J. W., Atwood, D. K., Leonard, J. J., and Chryssostomidis, C. A second generation survey AUV. In Proceedings of IEEE Symposium on Autonomous Underwater Vehicle Technology. Cambridge, MA, USA, pages 148-155, 1994. doi:10.1109/AUV.1994. 518619.

Blondel, P. The handbook of sidescan sonar. Springer, 2010.

Britting, K. R. Inertial navigation system analysis. John Wiley \& Sons Inc., 1971.

Carreño, S., Wilson, P., Ridao, P., and Petillot, Y. A survey on terrain based navigation for AUVs. In OCEANS. Seattle, WA, USA, pages 1-7, 2010. doi:10.1109/OCEANS. 2010.5664372.

Cruz, N. A. and Matos, A. C. Reactive AUV motion for thermocline tracking. In OCEANS. Sydney, Australia, pages 1-6, 2010. doi:10.1109/OCEANSSYD. 2010.5603883.

Eik, K. Review of experiences within ice and iceberg management. Journal of Navigation, 2008. 61(4):557. doi:10.1017/S0373463308004839.

Eik, K. and Løset, S. Specifications for a subsurface ice intelligence system. In Proceedings of the ASME 28th International Conference on Ocean, Offshore and Arctic Engineering. Honolulu, HI, USA, pages 103-109, 2009. doi:10.1115/OMAE2009-79606. 
Farmer, G. T. and Cook, J. Climate change trends. In: Climate change science: A modern synthesis, volume 1 - The Physical Climate. Springer, 2013. doi:10.1007/978-94-007-5757-8_5.

Ferguson, J. The Theseus autonomous underwater vehicle. Two successful missions. In Proceedings of International Symposium on Underwater Technology. Tokyo, Japan, pages 109-114, 1998. doi:10.1109/ UT. 1998.670072.

Ferguson, J. Adapting AUVs for use in under-ice scientific missions. In OCEANS. Quebec City, QC, Canada, pages 1-5, 2008. doi:10.1109/0CEANS. 2008.5152025 .

Ferguson, J. $1000 \mathrm{~km}$ under ice with an AUV - Setting the stage for future achievement. In IEEE Symposium on Underwater Technology and Workshop on Scientific Use of Submarine Cables and Related Technologies. Tokyo, Japan, pages 1-5, 2011. doi:10.1109/UT.2011.5774171.

Forrest, A. L., Hamilton, A. K., Schmidt, V., Laval, B. E., Mueller, D., Crawford, A., Brucker, S., and Hamilton, T. Digital terrain mapping of Petermann Ice Island fragments in the Canadian High Arctic. In Proceedings of the 21st IAHR International Symposium on Ice. Dalian, China, pages 710-721, 2012.

Forrest, A. L., Laval, B., Doble, M. J., Yeo, R., and Magnusson, E. AUV measurements of under-ice thermal structure. In $O C E A N S$. Quebec City, QC, Canada, pages 1-10, 2008. doi:10.1109/0CEANS. 2008.5152046.

Francois, R. and Nodland, W. Unmanned Arctic research submersible (UARS) system development and test report. Technical Report No. APL-UW 7219, University of Washington, 1972.

Freitag, L., Koski, P., Morozov, A., Singh, S., and Partan, J. Acoustic communications and navigation under Arctic ice. In OCEANS. Hampton Roads, VA, USA, pages 1-8, 2012. doi:10.1109/OCEANS. 2012. 6405005.

Gade, K. NavLab, a generic simulation and postprocessing tool for navigation. European Journal of Navigation, 2004. 2(4):1-9.

Gautier, D. L., Bird, K. J., Charpentier, R. R., Grantz, A., Houseknecht, D. W., Klett, T. R., Moore, T. E., Pitman, J. K., Schenk, C. J., Schuenemeyer, J. H., Sørensen, K., Tennyson, M. E., Valin, Z. C., and Wandrey, C. J. Assessment of undiscovered oil and gas in the Arctic. Science, 2009. 324:1175-1179. doi:10.1126/science.1169467.
Hagen, P. E., Midtgaard, Ø., and Hasvold, Ø. Making AUVs Truly Autonomous. In OCEANS. Vancouver, BC, Canada, pages 1-4, 2007. doi:10.1109/0CEANS. 2007.4449405.

Haugen, J., Imsland, L., Løset, S., and Skjetne, R. Ice observer system for ice management operations. In Proceedings of the 21th International Offshore and Polar Engineering Conference. Maui, HI, USA, pages 1120-1127, 2011.

Hobson, B. W., McEwen, R. S., Erickson, J., Hoover, T., McBride, L., Shane, F., and Bellingham, J. G. The Development and Ocean Testing of an AUV Docking Station for a 21" AUV. In OCEANS. Vancouver, BC, Canada, pages 1-6, 2007. doi:10.1109/ OCEANS . 2007 . 4449318.

Imagenex. Model 837/A/B DeltaT Multibeam Sonar System (operator manual and supporting documents). Imagenex Technology Corp., 2011.

Jalving, B., Gade, K., Svartveit, K., Willumsen, A., and Sørhagen, R. DVL velocity aiding in the HUGIN 1000 integrated inertial navigation system. Modeling, Identification and Control, 2004. 25(4):223-236. doi:10.4173/mic.2004.4.2.

Johnson, M., Herold, D., and Catipovic, J. The design and performance of a compact underwater acoustic network node. In OCEANS, volume 3. Brest, France, pages 467-471, 1994. doi:10.1109/0CEANS. 1994.364243.

Jørgensen, U. and Skjetne, R. Online reconstruction of drifting underwater ice topography: The 2D case. Asian Journal of Control, 2015. Accepted for publication.

Kaminski, C., Crees, T., Ferguson, J., Forrest, A., Williams, J., Hopkin, D., and Heard, G. 12 days under ice - an historic AUV deployment in the Canadian High Arctic. In IEEE/OES Autonomous Underwater Vehicles. Monterey, CA, USA, pages 1-11, 2010. doi:10.1109/AUV . 2010.5779651.

Kimball, P. and Rock, S. Sonar-based iceberg-relative AUV navigation. In IEEE/OES Autonomous Underwater Vehicles. Woods Hole, MA, USA, pages 1-6, 2008. doi:10.1109/AUV.2008.5290534.

King, P., Lewis, R., Mouland, D., and Walker, D. CATCHY An AUV ice dock. In OCEANS. Biloxi, MS, USA, pages 1-6, 2009.

Kinsey, J. C., Eustice, R. M., and Whitcomb, L. L. A survey of underwater vehicle navigation: Recent 
advances and new challenges. In Conference of $M a-$ noeuvering and Control of Marine Craft. Lisbon, Portugal, pages 1-12, 2006.

Kunz, C., Murphy, C., Singh, H., Pontbriand, C., Sohn, R. A., Singh, S., Sato, T., Roman, C., Nakamura, K.-i., Jakuba, M., Eustice, R., Camilli, R., and Bailey, J. Toward extraplanetary under-ice exploration: Robotic steps in the Arctic. Journal of Field Robotics, 2009. 26(4):411-429. doi:10.1002/ rob. 20288.

L-3 Communications. Multibeam sonar theory of operation. 2000. URL http://www.Ideo.columbia. edu/res/pi/MB-System/sonarfunction/ SeaBeamMultibeamTheoryOperation.pdf.

Laxon, S. W., Giles, K. A., Ridout, A. L., Wingham, D. J., Willatt, R., Cullen, R., Kwok, R., Schweiger, A., Zhang, J., Haas, C., Hendricks, S., Krishfield, R., Kurtz, N., Farrell, S., and Davidson, M. CryoSat2 estimates of Arctic sea-ice thickness and volume. Geophysical Research Letters, 2013. 40(4):732-737. doi:10.1002/grl.50193.

Lubin, D. and Massom, R. Polar remote sensing: Volume1: Atmosphere and oceans. Springer, 2006.

McEwen, R., Thomas, H., Weber, D., and Psota, F. Performance of an AUV navigation system at Arctic latitudes. IEEE Journal of Oceanic Engineering, 2005. 30(2):443-454. doi:10.1109/JOE. 2004. 838336 .

Milne, P. H. Underwater acoustic positioning system. E. \& F. N. Spon Ltd, London, 1983.

Moline, M. A., Blackwell, S. M., von Alt, C., Allen, B., Austin, T., Forrester, N., Goldsborough, R., Purcell, M., and Stokey, R. Remote environmental monitoring units: An autonomous vehicle for characterizing coastal environments. Journal of Atmospheric and Oceanic Technology, 2005. 22:17971808. doi:10.1175/JTECH1809.1.

National Snow and Ice Data Center. Arctic sea ice reaches minimum extent for 2014. 2014. URL http://nsidc.org/arcticseaicenews/2014/09/ arctic-minimum-reached/. (Accessed: 07 Nov. 2014).

Nilssen, I., Ødegård, Ø., Sørensen, A. J., Johnsen, G., Moline, M. A., and Berge, J. Integrated environmental mapping and monitoring: a methodological approach to optimise knowledge gathering and sampling strategy through use of a case study from Svalbard, Norway, 2015. To be pubished.
Norgren, P., Lubbad, R., and Skjetne, R. Unmanned underwater vehicles in Arctic operations. In Proceedings of the 22nd IAHR International Symposium on Ice. Singapore, pages 89-101, 2014. doi:10.3850/ 978-981-09-0750-1_1146.

O'Connell, B. J. Marine radar for improved ice detection. Technical report, Canadian Coast Guard, Ottawa, Ontario, Canada, 2008. URL http://www . dfo-mpo.gc.ca/library/343421.pdf.

O'Hara, C. A. and Collis, J. M. Acoustics in Arctic environments. In 162nd Acoustical Society of America Meeting. San Diego, CA, USA, pages 1-2, 2011. URL http://inside.mines.edu/ jcollis/ Pekerice_Lay_Language_Paper.pdf.

Rice, J. SeaWeb acoustic communication and navigation networks. In Proceedings of the International Conference on Underwater Acoustic Measurements: Technologies and Results. Heraklion, Greece, pages $1-7,2005$.

Santos, N., Matos, A., and Cruz, N. Navigation of an autonomous underwater vehicle in a mobile network. In $O C E A N S$. Quebec City, QC, Canada, pages 1-5, 2008. doi:10.1109/OCEANS . 2008.5151980.

Sear, C. B. and Wadhams, P. Statistical properties of Arctic sea-ice morphology derived from sidescan sonar images. Progress in Oceanography, 1992. 29(2):133-160. doi:10.1016/0079-6611(92) 90022-R.

Stojanovic, M. Recent advances in high-speed underwater acoustic communications. IEEE Journal of Oceanic Engineering, 1996. 21(2):125-136. doi:10.1109/48.486787.

Teledyne RD Instruments. Acoustic Doppler current profiler: Principles of operation: A practical primer. 2011. URL http://ww.rdinstruments. com/support/SoftwareFirmware/x/cs/files/ Manuals/BBPRIME.pdf.

Thomson, J. and Rogers, W. E. Swell and sea in the emerging Arctic Ocean. Geophysical Research Letters, 2014. 41(9):3136-3140. doi:10.1002/ 2014 GL059983.

Thorleifson, J., Davies, T., Black, M., Hopkin, D., Verrall, R., Pope, A., Monteith, I., Den Hertog, V., and Butler, B. The Theseus autonomous underwater vehicle. A Canadian success story. In OCEANS. Halifax, NS, Canada, pages 1001-1006, 1997. doi:10.1109/OCEANS . 1997.624127. 
Timco, G. and Burden, R. An analysis of the shapes of sea ice ridges. Cold Regions Science and Technology, 1997. 25(1):65-77. doi:10.1016/S0165-232X (96) 00017-1.

Wadhams, P. Sidescan sonar imagery of sea ice in the Arctic Ocean. Canadian Journal of Remote Sensing, 1978. 4(2):161-173. doi:10.1080/07038992.1978. 10854978.

Wadhams, P., Wilkinson, J. P., and Kaletzky, A. Sidescan sonar imagery of the winter marginal ice zone obtained from an AUV. Journal of Atmospheric and Oceanic Technology, 2004. 21(9):14621470. doi:10.1175/1520-0426(2004)021<1462: SSIOTW>2. 0 . CO;2.

Wadhams, P., Wilkinson, J. P., and McPhail, S. D. A new view of the underside of Arctic sea-ice. Geophysical Research Letters, 2006. 33(4):L04501. doi:10. 1029/2005GL025131.

Wiig, M. S., Krogstad, T. R., and Midtgaard, Ø. Autonomous identification planning for mine countermeasures. In IEEE/OES Autonomous Underwater Vehicles (AUV). IEEE, Southampton, U.K., pages 1-8, 2012. doi:10.1109/AUV . 2012.6380733. 